\title{
Building Competitive Advantage for Vietnamese Firms: The Roles of Knowledge Sharing and Innovation
}

\author{
Son Thanh Than ${ }^{1}$, Cung Huu Nguyen ${ }^{1}$, Thang Quang $\operatorname{Tran}^{1} \&$ Phong Ba Le ${ }^{1}$ \\ ${ }^{1}$ Faculty of Business Administration, Hanoi University of Industry, Bac Tu Liem District, Hanoi, Vietnam \\ Correspondence: Phong Ba Le, Hanoi University of Industry, 298 Cau Dien Street, Bac Tu Liem District, Hanoi, \\ Vietnam. Email: lebaphong@haui.edu.vn
}

Received: April 28, 2019

Accepted: May 13, 2019

Online Published: May 27, 2019

doi:10.5430/ijba.v10n4p1

URL: https://doi.org/10.5430/ijba.v10n4p1

\begin{abstract}
The purpose of this study is to investigate the influence of knowledge sharing (KS) and two specific types of innovation on competitive advantage in Vietnamese firms. Based on using structural equation modeling (SEM) and survey data collected from 225 participants, the findings reveal that KS directly and indirectly affects firm's competitive advantage through the mediating role of innovation speed and innovation quality. The findings stress the important role of building a positive climate to stimulate employees for sharing knowledge aimed at improving firm's innovation capability, and sustaining competitive advantage. Future research needs to explore the relationship between three components of knowledge management namely knowledge acquisition, KS, and knowledge application, innovation, and specific aspects of competitive advantage (such as low cost advantage, differentiation advantage, and time advantage) to provide deeper the mechanism of how specifics aspects of knowledge management connected with firm's certain types of competitive advantage through innovation.
\end{abstract}

Keywords: knowledge sharing, innovation, innovation speed, innovation quality, competitive advantage

\section{Introduction}

The 21 st century requires firms to focus on knowledge, information and innovation to development. The success of an organization mainly depends on employees' knowledge, experience, creative activity and firm's innovation capability (Urbancova, 2013; Le \& Lei, 2019). Improving innovation capability is seen as one of the key solutions for firms to effectively respond to quickly change of business environment, and create competitive advantage in long term (Urbancova, 2013; Skinnarl et al., 2014; Le \& Lei, 2019; Nguyen et al., 2019). Innovation is widely recognized as a core dynamic capability which allows firms to achieve competitive advantage in many facets like market performance, production shortening, market share maintenance, and accelerating new products development (Tidd et al., 2006), operational efficiency and service quality (Hsueh \& Tu, 2004; Parasuraman, 2010), developing new capabilities, and meeting customer's needs (Calantone et al., 2002; Sadikoglu \& Zehir, 2010) compared with key competitors. As a result, leaders and their organization are attempting to innovate (Hogan \& Coote, 2014; Skinnarl et al., 2014; Yang et al., 2018). However, most of them is still imitators and are struggling to become innovators (Song, 2015; Le \& Lei, 2019). Thus, exploring the potential factors that significantly enhance firms' innovation capability to develop firm's competitive advantage is very needful and meaningful.

Previous studies pointed out that knowledge sharing (KS) is the main root that notably stimulates employees to share more ideas and knowledge for innovation and competitive advantage (Donate \& Guadamillas, 2011; Skinnarl et al., 2014). However, the research on the relationship between KS, innovation and competitive advantage is still sparse (Skinnarl et al., 2014; Yang et al., 2018). With the aim of clarifying the relationship among these factors, this study is done to investigate the mediating role of innovation speed and innovation quality in the relationship between KS and competitive advantage in case of Vietnamese firms. The research topic is new and meaningful for firms by following reasons.

First, KS and improving firm's innovation capability are the important topics that attracted great interested from scholars and practitioners today (Breznik \& Hisrich, 2014; Leavy, 2015; Le \& lei, 2018; Le \& Lei, 2019). Although knowledge sharing-innovation relationship is shown clearly by prior researches, the understanding on the correlation among these factors is still needed to explore, especially in case of examining the effects of KS on specific aspects of innovation. Consequently Anderson et al. (2014) posed the question that: "What is the relationship between 
organizational resources and different types of organizational innovation?" Meanwhile, KS is popularly viewed as one of important resources of organization (Wang \& Noe, 2010; Le \& Lei, 2019). As a result, investigating the correlation between KS and two specific aspects of innovation namely innovation speed and innovation quality will positively address this issue.

Second, although KS is considered as an important antecedent of competitive advantage few researches explained KS-competitive advantage relationship in case of Vietnamese firms. Moreover, according to Ma et al. (2008), "the theory of knowledge management and knowledge sharing was created in the West", few studies have been done and explored the concept and influence of KS on firms in the context of developing country like Vietnam. Thus, investigating the correlation between KS and competitive advantage associated with the collectivistic essence of Vietnamese culture will produce the valuable understanding for scholars and practitioner.

Finally, prior research pointed out that most firms consider knowledge and innovation as the key foundations of organizational capabilities to compete in a dynamic environment (Skinnarl et al., 2014; Tamayo-Torres et al., 2016). However, studies of the complex interactions among KS, innovation and competitive advantage are still lacking. Resulting in the contributions of KS and innovation to competitive advantage remains unclear (Skinnarl et al., 2014; Tamayo-Torres et al., 2016). Given such situation, this study investigates the mediating role of innovation to clarify the correlation among the constructs.

Based on above argument, the authors realize that although previous works have made a considerable contribution to the understanding of the relationship between KS, innovation, and competitive advantage, the empirical research that explain clearly mechanism of how KS affect innovation to improve competitive advantage is still sparse and limited, especially in Vietnam context. To fill the theoretical and practical gaps, this study proposal a research model to investigate the influence of $\mathrm{KS}$ on competitive advantage through the mediating roles of innovation speed and innovation quality by posing following research questions:

RQ1. Does KS have positive influence on aspects of innovation capability?

RQ2. Do innovation capabilities have positive influence on competitive advantage?

RQ3. Do innovation capabilities mediate between KS and competitive advantage?

To answer the above research question, this study uses the structural equation modeling to examine the level of influence that independent factors have on the dependent ones based on a survey of 225 participants from 107 firms in Vietnam. Our research is expected to provide both theoretical initiatives and practical implication on the relationship between KS, innovation capability, and firm's competitive advantage.

The remainder of this study is organized as follows. The section 2 reviews the current literature to present three related concepts in proposed model and develops a research model to portray hypothesized relationship. Section 3 presents the data collection and research method to examine the proposal research model. Part 4 analyzes the data and discusses the empirical results. Finally, section 5 will discuss to give managerial implications, its limitations, and makes proposals for future research.

\section{Literature Review}

\subsection{Knowledge Sharing and Innovation Capability}

Knowledge is well known as the invisible and valuable resource of an organization. Davenport and Prusak (1998, p.5) defined knowledge with following characteristics: "A fluid mix of framed experience, values, contextual information, and expert insight that provides a framework for evaluating and incorporating new experiences and information. It originates and is applied in the minds of knowers. In organizations, it often becomes embedded not only in documents or repositories but also in organizational routines, processes, practices, and norms". Organizational knowledge is disseminated within an organization as valid information that has been established through the tests of proof (Liebeskind, 1996; Hsu, 2008). This information significantly supports and guides employees in their decisions or judgments to improve job performance and ultimately, competitive advantage of organizations (Tsoukas \& Vladimirou, 2001; Hsu, 2008). Le and Lei (2019), supposed that the effectiveness in the process of sharing knowledge is the determinant of an organization's success. As a result, this topic attracted great attention from scholars and practitioners (e.g., Tamayo-Torres et al., 2016; Le \& Lei, 2017; Le \& Lei, 2018b; Farooq, 2018; Le et al., 2018). KS refers to the process of transferring or disseminating knowledge from one person, or group to another (Hsu, 2008). Van den Hooff and De Ridder (2004) defined KS as the process of exchanging knowledge, jointly creates new knowledge between employees in the organization. 
Innovation that is a dynamic capacity of an organization enables firms to respond effectively to the rapid changes of business environment (Le \& Lei, 2019). According to Baregheh et al. (2009), "there are many different definitions of innovation in current research, and overall the number and diversity of definitions leads to a situation in which there is no clear and authoritative definition of innovation". However, innovation mainly refers to the process of the introduction and implementation of new ideas, products, services, procedures, technology, organizational structures, plans and programs, with the purpose of increasing organizational performance, and achieving organizational success (Kaasa \& Vadi, 2010; Rujirawanich et al., 2011). Previous studies classified innovation into various categories such as product innovation, process innovation, and managerial innovation (Tsai et al., 2001); technical innovation, and administrative innovation (Damanpour, 1991); innovation speed, and innovation quality (Wang \& Wang, 2012). Among which, innovation speed and innovation quality are considered as two critical aspects of innovation (Le \& Lei, 2018). Consequently, this study focuses on investigating the relationship between knowledge sharing and the two aspects of innovation capability to generate competitive advantage for firms. Innovation speed reflects the ability of firm in shortening the creation of new products, service or processes relative to the key competitors (Allocca \& Kessler, 2006; Le \& Lei, 2018); and innovation quality reflects the ability of firm in improving new management, processes and supply new products and services with better quality than key competitors (Wang et al., 2016; Le \& lei, 2018).

Prior researches highlight KS as an important precursor of innovation capability (Jantunen, 2005; Lin, 2007; Podrug et al., 2017; Le \& Lei, 2019). Specifically, Jantunen (2005) asserted that KS among employees may help firms to have superior innovation capability because firms can only perform effectively manage knowledge if employees are willing to sharing their knowledge with the others. Promoting KS practices within groups and/or organizations may increase firms' capability to generate new ideas for developing new business opportunities, and consequently facilitating innovation activities (Lundvall \& Nielsen, 2007; Heffner \& Sharif, 2008). Wang and Wang (2012) supposed that KS process contributes to innovations in teams, units and the entire organization. Their empirical researches indicated that KS is the important factor affected both firms' innovation speed and innovation quality. Podrug et al. (2017) pointed out that the willingness of employee to donate and collect knowledge significantly contributes to improving innovation capability for organization. Recently, Le and Lei (2019) stressed that KS positively affect firm's innovation capabilities in term of product and process innovation.

Above arguments support positive effects of KS on innovation capability. To have clearer understanding on the relationship between KS and two specifics types of innovation namely innovation speed and innovation quality, we proposed following hypotheses:

\section{Hla. KS has positive impacts on innovation speed.}

HIb. KS has positive impacts on innovation quality.

\subsection{Knowledge Sharing and Competitive Advantage}

Competitive advantage refers to firm's core competencies that allow firm to consistently outperform, and achieve a unique position relative to key competitors (Porter, 1985). Core competencies involve the particular set of skills and resources that a firm possesses as well as the way firm used these resources to produce outcomes. Scholars widely accepted that these competencies must be superior and inimitable by rivals to provide a sustainable competitive advantage (Reed \& DeFillippi, 1990; Fiol, 2001; Le \& Lei, 2018). Lei et al. (2017) argued that "an organization is said to achieve a competitive advantage if it occupied some positions by implementing a value creating strategy and gaining sustainable benefits from the strategy, simultaneously competitors are unable to copy its successful strategy". These authors highlighted the important role of organizational knowledge established by organizational learning to positively affect competitive advantage of firms. According to Davenport and Prusak (1998) knowledge is a critical resource that helps organizations to build sustainable competitive advantage in a competitive and dynamic economy. Teece (2007) confirmed that knowledge is a kind of valuable intangible assets for creating and sustaining competitive advantages. Consequently, management of available knowledge resources becomes extremely important for every organization. KS is one of the most crucial elements of knowledge management (Le \& Lei, 2017; Le \& Lei, $2018 \mathrm{c}$ ), so investigating the correlation between KS and competitive advantage is very necessary for firms to have clearer understanding of knowledge sharing's influence on key outcomes of organizations.

Prior researches showed evidence for the correlation between knowledge, KS and competitive advantage. KS positively related to competitive advantage because it helps employees to consider more options based on learning from the other's experiences and using better the knowledge through interaction each other. These lead to improved decision making and better problem solving (Davenport et al., 1996; Salisbury, 2001). By using data collected from a convenience sample of 112 senior managers, Almahamid et al.'s (2010) empirical research indicated that KS 
practices have a significant positive effect on competitive advantage of firms in Jordan. By using case study in one of largest hotel companies in Scandanavia, Skinnarl et al. (2014) showed that if an organization can stimulate process of sharing knowledge and enhance its learning, it should become more effective in competition.

Above discussions support the positive relationship between KS and competitive advantage. However the empirical study clearly explains mechanism of how KS fosters competitive advantage is still limited. We, therefore, propose following hypothesis (see Figure 1).

\section{H2. KS positively effects on competitive advantage}

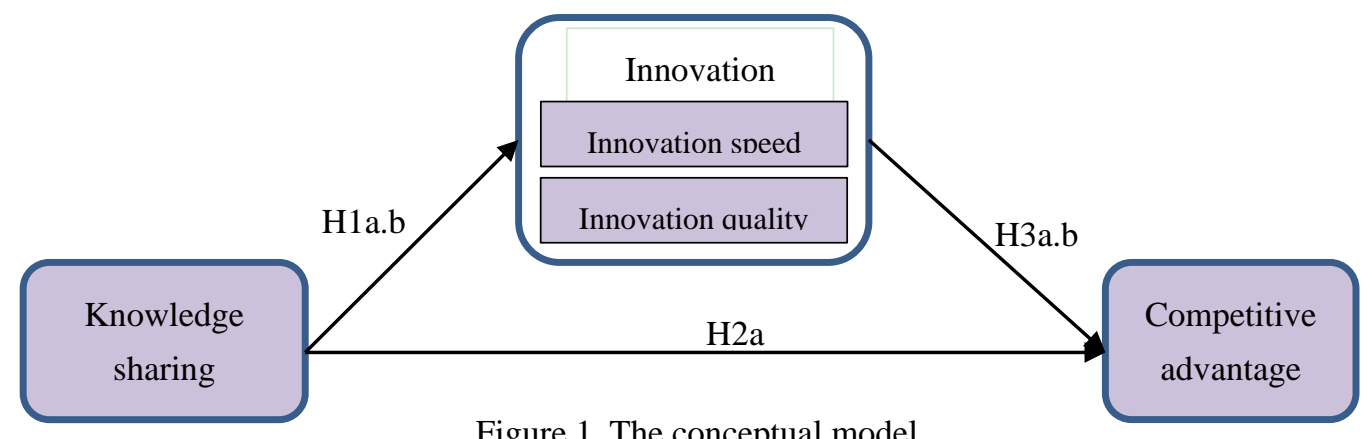

Figure 1. The conceptual model

\subsection{Innovation Capability and Competitive Advantage}

Innovation has been recognized as an important factor for firms to create value and to have a great influence on competition (Mintzberg, 1994). According to Wang and Wang (2012), innovation allows firms to make full use of existing resources, to improve efficiency and potential value, and to bring new intangible assets into organization. Innovation helps firms gain a competitive advantage in several aspects: market performance, market share maintenance, production shortening and accelerating new products development (Tidd et al., 2006); operational efficiency and service quality (Hsueh \& Tu, 2004; Parasuraman, 2010); meeting customer's needs, developing new capabilities, performance or superior profitability (Calantone et al., 2002; Sadikoglu \& Zehir, 2010) in comparison with competitors. Success in technology innovation enables firms to create and to maintain a competitive advantage (Martin-de Castro et al., 2013). Le and lei (2018) showed the evidence that innovation speed and innovation quality positively associated with competitive advantage in case of Chinese firm. Recently, Nguyen et al. (2019) supposed that, innovation capability is associated with competitive advantage in case of Vietnamese firms because it enables firms to make full use of existing resources to boost organization's efficiency and potential values.

In conclusion, the positive relationships between innovation and competitive advantages are discussed and explored by a many previous researches. Especially, Weerawardena and Mavondo (2011) suggested that "all types of innovation contribute to a firm's competitive advantages", few researches consider the specific effects of innovation on two kinds of competitive advantages (Nguyen et al., 2019). So this study proposes two more hypotheses (see Figure 1).

\section{H3a. Innovation speed has positive impact on competitive advantage}

H3b. Innovation quality has positive impact on competitive advantage

\section{Research Methodology}

\subsection{Sample and Data Collection}

This study used convenient sampling method to collect data from both manufacturing and service firms in Vietnamese. We communicated with representatives of these firms who mainly worked in human resources departments by phone and/or make personal visits to explain the purpose of the research, committing to information security for respondents, and ask for their assistance in collecting. The respondents in this study need to be key employees who are directors/managers, head of departments, team leaders, and employees at departments of administration to ensure having full understanding on firm's business situation. Questionnaires were sent directly to these representatives by personal visits between June and August 2018. This study issues 560 questionnaires and receives 366 ones in the formal data collection, among which 225 ones are valid, with a $40.1 \%$ valid rate. 


\subsection{Variable Measurement}

To ensure the validity and reliability of the study, the measurement items are adapted from exiting scales in the literature that have been developed and used from previous studies. All constructs were measured using multiple items and all items are measured via five-point Likert-type scales, ranging from "1" (strongly disagree) to "5" (strongly agree) or from " 1 " (strongly unwilling to) to 5 (strongly willing to).

\subsubsection{Knowledge Sharing}

We used four items adapted from the research of Faraj and Sproull (2000) to measure perceptions of KS by employees. A sample item is: "More knowledgeable employees freely provide other colleagues with hard-to-find knowledge or specialized skills"

\subsubsection{Innovation Speed and Quality}

In order to measure innovation speed and innovation quality, we use 10 items derived from the research of Le \& Lei (2018) to evaluate (1) innovation speed (five items) that reflect firm quickness to generate novel ideas, new product launching, new product development, new process, new problem solving as compared to key competitors, A sample item is "Our organization is quick in coming up with novel ideas as compared to key competitors"; and (2) Innovation quality (five items) that reflect firm quality to carry out new ideas, products, processes, practices and management of certain company. A sample item is "Our organization does better in new product development as compared to key competitors".

\subsubsection{Competitive Advantage}

To measure competitive advantage, four items derived from the study of Su et al. (2009) are applied to reflect firm's ability in occupying some position and attaining the sustainable benefits from the successful strategy where the competitors cannot copy its successful strategy. A sample item is: "Our company is the first mover in some important fields and occupies the important position."

\subsection{Data Analysis Methods}

The collected data is processed and translated into statistical results by using the software of SPSS and AMOS version 21. In addition, a bootstrapping procedure was used for the significance tests of the research hypotheses.

\section{Results}

\subsection{Measurement Model}

We firstly carried out an exploratory factor analysis (EFA) to eliminate factors had factor loading lower than 0.5 to ensure the practicality of the research (Hair at al., 1998). We then performed confirmatory factor analysis (CFA) to evaluate the overall measurement model to evaluate the validity of measurement model. We accessed convergent validity by considering factor loading (which should exceed 0.5 ); composite reliabilities (CR) (which should exceed 0.6); and the average variance extracted (AVE) (which should be greater than 0.5 for all constructs (Fornell \& Larcker, 1981). Besides, the internal reliability of scales are well if Crombach's alpha $(\mathrm{C} \alpha)$ is higher than 0.7 (Nunnly \& Bernstein, 1994). Table 1 shows that the research model met the convergent validity criteria.

Table 1. CFA and internal reliable testing results

\begin{tabular}{|c|c|c|c|c|c|c|c|}
\hline Construct & Mean & $\mathrm{SD}$ & Item & Loading & AVE & $\mathrm{CR}$ & $\mathrm{C} \alpha$ \\
\hline \multirow[t]{4}{*}{ Knowledge sharing (KS) } & 3.56 & 0.64 & KS1 & $0.89 * * *$ & 0.75 & 0.92 & 0.92 \\
\hline & & & KS2 & $0.84 * * *$ & & & \\
\hline & & & KS3 & $0.92 * * *$ & & & \\
\hline & & & KS4 & $0.81 * * *$ & & & \\
\hline \multirow[t]{5}{*}{ Innovation speed (IS) } & 3.58 & 0.58 & IS1 & $0.81 * * *$ & 0.75 & 0.94 & 0.93 \\
\hline & & & IS2 & $0.97 * * *$ & & & \\
\hline & & & IS3 & $0.95 * * *$ & & & \\
\hline & & & IS4 & $0.70 * * *$ & & & \\
\hline & & & IS5 & $0.87 * * *$ & & & \\
\hline Innovation quality (IQ) & 3.71 & 0.62 & IQ1 & $0.80^{* * *}$ & 0.83 & 0.96 & 0.96 \\
\hline
\end{tabular}




\begin{tabular}{|c|c|c|c|c|c|c|c|}
\hline & & & IQ2 & $0.97 * * *$ & & & \\
\hline & & & IQ3 & $0.85^{* * *}$ & & & \\
\hline & & & IQ4 & $0.94 * * *$ & & & \\
\hline & & & IQ5 & $0.97 * * *$ & & & \\
\hline \multirow[t]{4}{*}{ Competitive advantage (CA) } & 3.75 & 0.58 & CA1 & $0.94 * * *$ & 0.79 & 0.94 & 0.94 \\
\hline & & & CA2 & $0.83 * * *$ & & & \\
\hline & & & CA3 & $0.82 * * *$ & & & \\
\hline & & & CA4 & $0.95^{* * *}$ & & & \\
\hline
\end{tabular}

Notes: $\mathrm{C} \alpha \geq 0.7$; composite reliability $\geq 0.7$; average variances extracted $\geq 0.5 ; * * * \mathrm{p}<0.001$.

Table 2 shows that the square root of AVE for each construct (diagonal elements in bold) is greater than the correlations among constructs in the model. In general, the results provide strong support for the construct reliability, as well as for the convergent and discriminant validity of the scales.

Table 2. Correlations and average variances extracted from constructs

\begin{tabular}{lllll}
\hline Constructs & KS & IS & IQ & CA \\
\hline Knowledge sharing (KS) & $\mathbf{0 . 8 7}$ & & & \\
\hline Innovation speed (IS) & 0.50 & $\mathbf{0 . 8 7}$ & & \\
\hline Innovation quality (IQ) & 0.55 & 0.62 & $\mathbf{0 . 9 1}$ & \\
\hline Competitive advantage (CA) & 0.57 & 0.54 & 0.55 & $\mathbf{0 . 8 9}$ \\
\hline
\end{tabular}

Note: Diagonal elements are the square root of the AVE and Off-diagonal elements are the correlations among constructs.

In order to measure the degree fit of the model we evaluated following indicators: absolute fit measures including Chi-square/df (CMIN/df), goodness of fit index (GFI) and root mean square error of approximation (RMSEA); incremental fit measures including normed fit index (NFI), adjusted goodness of fit index (AGFI) and comparative fit index (CFI); parsimonious fit measures including parsimony goodness-of-fit index (PGFI) and parsimony normed fit index (PNFI). With results shown in Table 3, all fit indices meet satisfactory levels. Therefore, it demonstrated that there was adequate reliability and validity in this study.

Table 3. Overall fit index of the CFA model

\begin{tabular}{lll}
\hline Fit index & Scores & Recommended threshold value \\
\hline Absolute fit measures & & \\
\hline CMIN/df & 1.902 & $\leq 2^{\mathrm{a}} ; \leq 5^{\mathrm{b}}$ \\
\hline GFI & 0.886 & $\geq 0.90^{\mathrm{a}} ; \quad \geq 0.80^{\mathrm{b}}$ \\
\hline RMSEA & 0.063 & $\leq 0.80^{\mathrm{a}} ; \leq 0.10^{\mathrm{b}}$ \\
\hline Incremental fit measures & & \\
\hline NFI & 0.946 & $\geq 0.90^{\mathrm{a}} ;$ \\
\hline AGFI & 0.850 & $\geq 0.90^{\mathrm{a}} ; \quad \geq 0.80^{\mathrm{b}}$ \\
\hline CFI & 0.974 & $\geq 0.90^{\mathrm{a}} ;$ \\
\hline Parsimonious fit measures & & \\
\hline PGFI & 0.669 & The higher the better \\
\hline PNFI & 0.798 & The higher the better \\
\hline
\end{tabular}

Note: a Acceptability: acceptable; b Acceptability: marginal. 


\subsection{Structural Model}

This section presents the main result of the hypothesis testing of the structural relationship among the latent variables (Table 4, Table 5 and Figure 2)

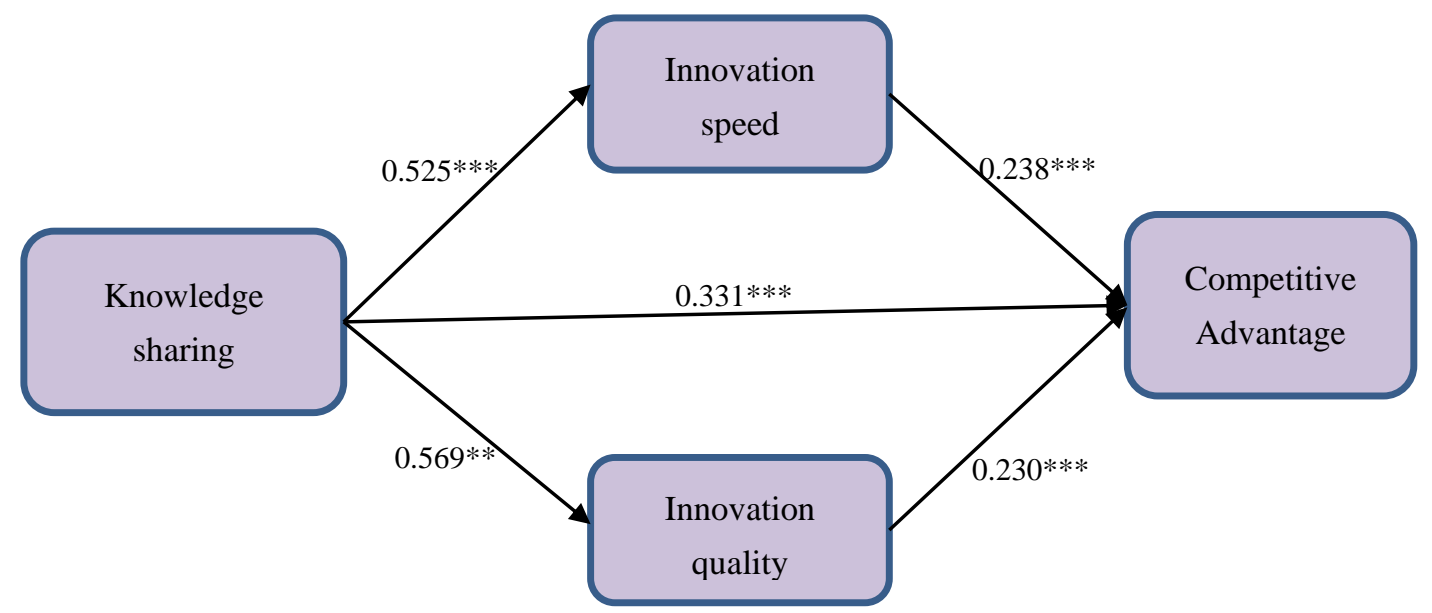

Figure 2. Results of the structural equation model

The results (Table 4 and Figure 2) indicated that the effect of KS on aspects of innovation capabilities is statistically significant and quite large, it supports hypotheses H1a and H1b. Specifically, KS's influence on innovation quality $(\beta$ $=0.569 ; p<0.001)$ is greater than its effects on innovation speed $(\beta=0.525 ; p<0.001)$.

Table 4. Structural model results

\begin{tabular}{lllll}
\hline Hypotheses & Proposal effect & $\beta$ & $\mathrm{P}$ & Results \\
\hline H1a: KS $\rightarrow$ IS & + & $0.525^{* * *}$ & $<0.001$ & Supported \\
\hline H1b: KS $\rightarrow$ IQ & + & $0.569^{* * *}$ & $<0.001$ & Supported \\
\hline H2: KS $\rightarrow$ CA & + & $0.331^{* * *}$ & $<0.001$ & Supported \\
\hline H3b: IS $\rightarrow$ CA + & $0.238^{* * *}$ & $<0.001$ & Supported \\
\hline H3b: IQ $\rightarrow$ CA + & $0.230^{* * *}$ & $<0.001$ & Supported \\
\hline
\end{tabular}

Note: ***significant at the 0.001 level; **significant at the 0.05 level; *significant at the 0.10 level

Hypothesis of $\mathrm{H} 2$ relating to the positive effect of $\mathrm{KS}$ on competitive advantage is also supported $(\beta=0.331 ; p<$ $0.001)$.

The results also confirm hypothesis of $\mathrm{H} 3 \mathrm{a}$ and $\mathrm{H} 3 \mathrm{~b}$ relating to the positive effects of innovation speed and innovation quality on competitive advantage. The findings show that innovation speed has a little greater impacts on competitive advantage $(\beta=0.238 ; p<0.001)$ in comparison with innovation quality's impacts on competitive advantage $(\beta=0.230 ; p<0.001)$.

Besides investigating the direct impacts of independent variables on dependent variable, this study also examine the mediating role of innovation capability between KS and competitive advantage. To show the evidence for the mediating mechanism of aspects of innovation capability, Bootstrap procedure is performed to evaluate the confidence of indirect effect. The Table 4 shows the direct, indirect, and total effects in structural model. 
Table 5. Direct, indirect and total effects analysis

\begin{tabular}{llll}
\hline Predictor/dependent & IS & IQ & CA \\
\hline Direct effects & & & \\
\hline Knowledge sharing (KS) & $0.525^{* * * *}$ & $0.569^{* * *}$ & $0.331^{* * *}$ \\
\hline Innovation speed (IS) & & $0.238^{* * *}$ \\
Innovation quality (IQ) & & $0.230^{* * *}$ \\
\hline Indirect effects & & \\
\hline Knowledge sharing (KS) & & $0.256^{* * *}$ \\
\hline Total effects & & \\
\hline Knowledge sharing (KS) & & $0.587^{* * *}$ \\
\hline
\end{tabular}

Notes: $* * *$ Significant at the 0,001 level

Table 5 firstly establishes the mediator of innovation speed and innovation quality in the correlation between KS and competitive advantage. Regarding total effects, Table 5 shows that total effects of KS on competitive advantage very positive and significant $(\beta=0.587 ; p<0.001)$.

\section{Discussions and Conclusions}

This study has developed a proposal research model to examine the relationship between KS, aspects of innovation capability namely innovation speed and innovation quality. The findings have supported all the proposal hypotheses that are posed initially. This study, therefore, significantly contributes to the literature of innovation management and competitive advantage in following ways.

The first, although firm innovation capability is widely prescribed as a driving force of enhancing organizational performance and competitive advantage (Hurley \& Hult, 1998; Garcia-Morales et al., 2008), scholars realized that organizations have to cope with many challenges to successfully innovate (Garcia-Morales et al., 2008; Le \& Lei, 2018). This leads to attention or motivation among researchers to look for what enables firms to innovate (Zollo \& Winter, 2002; Le \& Lei, 2018). Accordingly, this study significantly contributes to the improvement of innovation management theory by showing that innovation speed and innovation quality may be achieved based on building a positive climate which stimulating KS behavior among employees. From this finding, the major implication of the paper is that, innovation capabilities do not come to organization natural, it only occurs in cases of having certain condition or appropriate contexts (Ha et al., 2019). Among which KS can be seen as one of the most important antecedents to improve organizational capabilities for innovation. As a result, to foster the willingness of employees toward KS, firms need to pay great attention to building a positive climate that facilitates KS behaviors of employees such as developing a collaborative culture in their firms (Lei et al., 2017; Yang et al., 2018), building a climate of trust among employee and implementing procedural and distributional justice (Le \& Lei, 2017; Hui et al., 2018), and encouraging their managers to perform transformational leadership style (Van et al., 2018; Le \& Lei, 2019).

The second, the willingness of employees toward collecting and sharing knowledge is suggested having positive effect on many key outcomes of an organization such as organizational performance (Garcia-Morales et al., 2008; Wang et al., 2016); employees' affective commitment (Li et al. 2015); organizational citizenship behaviors (Jo et al., 2011) and so on. However, few researches test the influence of KS on competitive advantage. As a result, this study contributes to filling the theoretical gap by confirming that KS is one of the key organizational resources which lie in the center of competitiveness of an organization. Indeed, KS can be seen as a rare and valuable resource. The process of sharing expertise knowledge and information among employees enables them to form the core competencies (such as super skills, distinct ability, and excellent process to perform duties) to produce super superior outcomes in compared with key competitors. Moreover, although Vietnam is considered as an emerging market with the economic growth rate of Vietnam relatively high and stable in recent years (more than 6\%), Vietnam is still a developing country where the firms' technology level and capacity (especially the financial capacity/capital) are still small and limited. Nguyen and Rose (2009) pointed that Vietnamese firms are facing with many difficulties and quite sensitive to changes in technology and innovation. The main reason is that most of them are small and medium enterprises (account for approximately $98.1 \%$ in 2017); and they tend to lack of resources and R\&D capabilities to innovate and develop competitive advantage. Accordingly, the findings of this study imply that enhancing KS among employees can be one of the most effective and least expensive choices for firms to enhance innovation capability 
and produce super competitive advantage to survive and develop before the constant change of the business environment.

Finally, one significant contribution of this study is to investigate the relationship between KS, innovation capabilities and competitive advantage from a holistic perspective. Therefore, this study firstly confirms the mediating roles of innovation speed and innovation quality in the relationship between KS and competitive advantage. The findings highlighted that KS directly or indirectly affects firm's competitive advantage via the mediating role of innovation capability. The findings also reveal that KS has more significant impact on innovation quality in comparison with its effects on innovation speed. Consequently, this study has contributed to increasing the understanding of how firms can use its resources to develop specific types of innovation. Specifically, the results have shown a specific and useful road for firms to successfully improve innovation quality which is very important to bring differentiation competitive advantage for firms (Le \& Lei, 2018). This finding can be served as the reference for Vietnamese firms to develop competitive advantage. In a broader context, the paper implies that, by focusing on developing firms' key capability of innovation, organization can produce special goods and services at the high degree of quality and value to achieve sustainable competitive advantage (Maruso \& Weinzimmer, 2015; McGee \& Shook, 2015).

There are several limitations relating to methodology. Specifically, survey research is particularly limited in generalizability when non-probabilistic sampling and cross-sectional design are used. Future research can show deeper and clearer the findings by other alternative research design such as a longitudinal survey. Especially a longitudinal design research with both qualitative and quantitative approaches enables to provide a more comprehensive of the underlying process through which KS affects aspects of innovation and competitive advantage. Knowledge management that includes three components namely knowledge acquisition, knowledge sharing, and knowledge application, have important influences on innovation and competitive advantage (Chuang, 2004; Sheng et al., 2013; Lee et al., 2016). However this study only investigates the role of KS in the relationship with related constructs. Future research needs to explore deeper the relationship between the three components of knowledge management and specific aspects of competitive advantage (such as low cost advantage, differentiation advantage, and time advantage) to provide clearer the mechanism of how specifics aspects of knowledge management connected with firm's certain competitive advantage through innovation.

Conclusions: this study has developed an integrated model to link KS, aspects of innovation and competitive advantage, and provide the empirical evidence to highlight that KS and innovation capability significantly contribute to raising firm's competitive advantage. Thus, the findings are very valuable to generate more useful knowledge and insight about the specific and appropriate solution for CEOs/managers to improve innovation speed, innovation quality, and sustain competitive advantage for their firms especially in case of Vietnam.

\section{References}

Allocca, M. A., \& Kessler, E. H. (2006). Innovation speed in small and medium-sized enterprises. Creativity and Innovation Management, 15(3), 79-295. https://doi.org/10.1111/j.1467-8691.2006.00389.x

Almahamid, S., Awwad, A., \& McAdams, A. C. (2010). Effects of organizational agility and knowledge sharing on competitive advantage: an empirical study in Jordan. International Journal of Management, 27(3), 387.

Anderson, N., Potočnik, K., \& Zhou, J. (2014). Innovation and creativity in organizations: A state-of-the-science review, prospective commentary, and guiding framework. Journal of Management, 40(5), 1297-1333. https://doi.org/10.1177/0149206314527128

Baregheh, A., Rowley, J., \& Sambrook, S. (2009). Towards a multidisciplinary definition of innovation. Management Decision, 47(8), 1323-1339. https://doi.org/10.1108/00251740910984578

Breznik, L., \& D. Hisrich, R. (2014). Dynamic capabilities vs. innovation capability: are they related?. Journal of Small Business and Enterprise Development, 21(3), 368-384. https://doi.org/10.1108/JSBED-02-2014-0018

Calantone, R. J., Cavusgil, S. T., \& Zhao, Y. (2002). Learning orientation, firm innovation capability, and firm $\begin{array}{llll}\text { performance. Industrial marketing management, } & 31(6), & 515-524 .\end{array}$ https://doi.org/10.1016/S0019-8501(01)00203-6

Chuang, S. H. (2004). A resource-based perspective on knowledge management capability and competitive advantage: an empirical investigation. Expert Systems With Applications, 27(3), 459-465. https://doi.org/10.1016/j.eswa.2004.05.008 
Damanpour, F. (1991). Organizational innovation: A meta-analysis of effects of determinants and moderators. Academy of Management Journal, 34(3), 555-590. https://doi.org/10.5465/256406

Davenport, T. H., \& Prusak, L. (1998). Working knowledge: How organizations manage what they know. Harvard Business Press.

Davenport, T. H., Jarvenpaa, S. L., \& Beers, M. C. (1996). Improving knowledge work processes. MIT Sloan Management Review, 37(4), 53.

Donate, M. J., \& Guadamillas, F. (2011). Organizational factors to support knowledge management and innovation. Journal of Knowledge Management, 15(6), 890-914. https://doi.org/10.1108/13673271111179271

Faraj, S., \& Sproull, L. (2000). Coordinating expertise in software development teams. Management Science, 46(12), 1554-1568. https://doi.org/10.1287/mnsc.46.12.1554.12072

Fiol, C. M. (2001). Revisiting an identity-based view of sustainable competitive advantage. Journal of Management, 27(6), 691-699. https://doi.org/10.1177/014920630102700606

Fornell, C., \& Larcker, D. F. (1981). Evaluating structural equation models with unobservable variables and measurement error. Journal of Marketing Research, 18(1), 39-50. https://doi.org/10.1177/002224378101800104

Ha, A. T. L., Phong, L. B., \& Lei, H. (2019). Leadership and Organizational Learning: The Determinants of Innovation Speed and Innovation Quality in Vietnamese Firms. Journal of Management and Strategy, 10(1), 29-37. https://doi.org/10.5430/jms.v10n1p29

Hair, J. F. Jr., Anderson, R. E., Tatham, R. L., \& William, C. (1995). Black (1995), Multivariate data analysis with readings. New Jersy: Prentice Hall.

Heffner, M., \& Sharif, N. (2008). Knowledge fusion for technological innovation in organizations. Journal of Knowledge Management, 12(2), 79-93. https://doi.org/10.1108/13673270810859532

Hogan, S. J., \& Coote, L. V. (2014). Organizational culture, innovation, and performance: A test of Schein's model. Journal of Business Research, 67(8), 1609-1621. https://doi.org/10.1016/j.jbusres.2013.09.007

Hsu, I. C. (2008). Knowledge sharing practices as a facilitating factor for improving organizational performance through human capital: A preliminary test. Expert Systems With Applications, 35(3), 1316-1326. https://doi.org/10.1016/j.eswa.2007.08.012

Hsueh, L. M., \& Tu, Y. Y. (2004). Innovation and the operational performance of newly established small and medium enterprises in Taiwan. Small Business Economics, 23(2), 99-113. https://doi.org/10.1023/B:SBEJ.0000027663.84972.ac

Hui, L., Phouvong, S., \& Phong, L. B. (2018). Transformational Leadership Facilitates Innovation Capability: The Mediating Roles of Interpersonal Trust. International Journal of Business Administration, 9(3), 1-9. https://doi.org/10.5430/ijba.v9n3p1

Hurley, R. F., \& Hult, G. T. M. (1998). Innovation, market orientation, and organizational learning: an integration and empirical examination. The Journal of Marketing, 42-54. https://doi.org/10.1177/002224299806200303

Jantunen, A. (2005). Knowledge-processing capabilities and innovative performance: an empirical study. European Journal of Innovation Management, 8(3), 336-349. https://doi.org/10.1108/14601060510610199

Jo, S. J., \& Joo, B. K. (2011). Knowledge sharing: The influences of learning organization culture, organizational commitment, and organizational citizenship behaviors. Journal of Leadership \& Organizational Studies, 18(3), 353-364. https://doi.org/10.1177/1548051811405208

Kaasa, A., \& Vadi, M. (2010). How does culture contribute to innovation? Evidence from European countries. Economics of Innovation and New Technology, 19(7), 583-604. https://doi.org/10.1080/10438590902987222

Le, B. P., Lei, H., Phouvong, S., Than, T. S., Nguyen, T. M. A., \& Gong, J. (2018). Self-efficacy and optimism mediate the relationship between transformational leadership and knowledge sharing. Social Behavior and Personality: An International Journal, 46(11), 1833-1846. https://doi.org/10.2224/sbp.7242

Le, P. B., \& Lei, H. (2017). How transformational leadership supports knowledge sharing: Evidence from Chinese manufacturing and service firms. Chinese Management Studies, 11(3), 479-497. https://doi.org/10.1108/CMS-02-2017-0039 
Le, P. B., \& Lei, H. (2018). The effects of innovation speed and quality on differentiation and low-cost competitive advantage: The case of Chinese firms. Chinese Management Studies, 12(2), 305-322. https://doi.org/10.1108/CMS-10-2016-0195

Le, P. B., \& Lei, H. (2018a). Fostering knowledge sharing behaviours through ethical leadership practice: the mediating roles of disclosure-based trust and reliance-based trust in leadership. Knowledge Management Research \& Practice, 16(2), 183-195. https://doi.org/10.1080/14778238.2018.1445426

Le, P. B., \& Lei, H. (2018b). The mediating role of trust in stimulating the relationship between transformational leadership and knowledge sharing processes. Journal of Knowledge Management, 22(3), 521-537. https://doi.org/10.1108/JKM-10-2016-0463

Le, P. B., \& Lei, H. (2019). Determinants of innovation capability: the roles of transformational leadership, knowledge sharing and perceived organizational support. Journal of Knowledge Management, 23(3), 527-547. https://doi.org/10.1108/JKM-09-2018-0568

Leavy, B. (2015). Continuous innovation: unleashing and harnessing the creative energies of a willing and able community. Strategy \& Leadership, 43(5), 24-31. https://doi.org/10.1108/SL-06-2015-0051

Lee, M. C. (2016). Knowledge management and innovation management: best practices in knowledge sharing and knowledge value chain. International Journal of Innovation and Learning, 19(2), 206-226.

Lei, H., Le, P. B., \& Nguyen, H. T. H. (2017). How Collaborative Culture Supports for Competitive Advantage: The Mediating Role of Organizational Learning. International Journal of Business Administration, 8(2), 73-85.

Li, J., Yuan, L., Ning, L., \& Li-Ying, J. (2015). Knowledge sharing and affective commitment: the mediating role of psychological ownership. Journal of Knowledge Management, 19(6), 1146-1166.

Liebeskind, J. P. (1996). Knowledge, strategy, and the theory of the firm. Strategic Management Journal, 17(S2), 93-107. https://doi.org/10.1002/smj.4250171109

Lin, C. P. (2007). To share or not to share: Modeling tacit knowledge sharing, its mediators and antecedents. Journal of Business Ethics, 70(4), 411-428. https://doi.org/10.1007/s10551-006-9119-0

Lundvall, B. A., \& Nielsen, P. (2007). Knowledge management and innovation performance. International Journal of Manpower, 28(3/4), 207-223. https://doi.org/10.1108/01437720710755218

Ma, Z., Qi, L., \& Wang, K. (2008). Knowledge sharing in Chinese construction project teams and its affecting factors: an empirical study. Chinese Management Studies, 2(2), 97-108.

Martín-de Castro, G., Delgado-Verde, M., Navas-López, J. E., \& Cruz-González, J. (2013). The moderating role of innovation culture in the relationship between knowledge assets and product innovation. Technological Forecasting and Social Change, 80(2), 351-363. https://doi.org/10.1016/j.techfore.2012.08.012

Maruso, L. C., \& Weinzimmer, L. G. (2015). Developing a Normative Framework to Access Small-Firm Entry Strategies: A Resource-Based View. Journal of Small Business Strategy, 10(1), 1-12.

McGee, J. E., \& Shook, C. L. (2015). Repsponding to Industry Consolidation in Fragmented Industries: The Role of Capabilities in Small Business Survival. Journal of Small Business Strategy, 11(2), 21-32.

Mintzberg, H. (1994). The rise and fall of strategic planning: Preconceiving roles for planning, plans, planners, pp. 221-321. New York.

Nunnally, J. C., \& Bernstein, I. (1994). Elements of statistical description and estimation. Psychometric Theory (3rd ed.). McGraw-Hill , New York.

Nguyen, D. K., Phong, L. B., \& Hui, L. (2019). Creating Competitive Advantage for Vietnamese Manufacturing and Service Firms: The Role of Collaborative Culture and Innovation Capability. International Journal of Business Administration, 10(2), 32-42. https://doi.org/10.5430/ijba.v10n2p32

Nguyen, T. V., \& Rose, J. (2009). Building trust-Evidence from Vietnamese entrepreneurs. Journal of Business Venturing, 24(2), 165-182. https://doi.org/10.1016/j.jbusvent.2008.03.004

Parasuraman, A. (2010). Service productivity, quality and innovation: Implications for service-design practice and research. International Journal of Quality and Service Sciences, 2(3), 277-286.

Podrug, N., Filipović, D., \& Kovač, M. (2017). Knowledge sharing and firm innovation capability in Croatian ICT companies. International Journal of Manpower, 38(4), 632-644. https://doi.org/10.1108/IJM-04-2016-0077 
Porter, M. E. (1985). PorterCompetitive Advantage1985. Competitive Advantage. New York: Free Press.

Reed, R., \& DeFillippi, R. J. (1990). Causal ambiguity, barriers to imitation, and sustainable competitive advantage. Academy of Management Review, 15(1), 88-102. https://doi.org/10.5465/amr.1990.4308277

Rujirawanich, P., Addison, R., \& Smallman, C. (2011). The effects of cultural factors on innovation in a Thai SME. Management Research Review, 34(12), 1264-1279. https://doi.org/10.1108/01409171111186397

Sadikoglu, E., \& Zehir, C. (2010). Investigating the effects of innovation and employee performance on the relationship between total quality management practices and firm performance: An empirical study of Turkish firms. International Journal of Production Economics, 127(1), 13-26. https://doi.org/10.1016/j.ijpe.2010.02.013

Salisbury, M. (2001). An example of managing the knowledge creation process for a small work group. Management Learning, 32(3), 305-319. https://doi.org/10.1177/1350507601323002

Sheng, M. L., Chang, S. Y., Teo, T., \& Lin, Y. F. (2013). Knowledge barriers, knowledge transfer, and innovation competitive advantage in healthcare settings. Management Decision, 51(3), 461-478.

Skinnarl, K. I., Asa, I., \& Sharp, P. (2014). Knowledge Sharing (KS), Organizational Learning and Competitive Advantage in a Scandinavian Hotel Company.

Song, Z. H. (2015). Organizational learning, absorptive capacity, imitation and innovation: Empirical analyses of 115 firms across China. Chinese Management Studies, 9(1), 97-113.

Su, Y. S., Tsang, E. W., \& Peng, M. W. (2009). How do internal capabilities and external partnerships affect innovativeness?. Asia Pacific Journal of Management, 26(2), 309-331.

Tamayo-Torres, I., Gutiérrez-Gutiérrez, L. J., Llorens-Montes, F. J., \& Martínez-López, F. J. (2016). Organizational learning and innovation as sources of strategic fit. Industrial Management \& Data Systems, 116(8), $1445-1467$.

Teece, D. J. (2007). Explicating dynamic capabilities: the nature and microfoundations of (sustainable) enterprise performance. Strategic Management Journal, 28(13), 1319-1350. https://doi.org/10.1002/smj.640

Tidd, J., Bessant, J., \& Pavitt, K. (2006). Management de l'innovation: Intégration du changement technologique, commercial et organisationnel: De Boeck Supérieur.

Tsai, C. T., Huang, K. L., \& Kao, C. F. (2001). The relationships among organizational factors, creativity of organizational members and organizational innovation. Journal of Management, 18(4), 527-566.

Tsoukas, H., \& Vladimirou, E. (2001). What is organizational knowledge?. Journal of Management Studies, 38(7), 973-993. https://doi.org/10.1111/1467-6486.00268

Urbancova, H. (2013). Competitive advantage achievement through innovation and knowledge. Journal of Competitiveness, 5(1). https://doi.org/10.7441/joc.2013.01.06

Van den Hooff, B., \& De Ridder, J. A. (2004). Knowledge sharing in context: the influence of organizational commitment, communication climate and CMC use on knowledge sharing. Journal of Knowledge Management, 8(6), 117-130. https://doi.org/10.1108/13673270410567675

Van, N. T., Phong, L. B., \& Loan, L. T. (2018). Antecedents of Innovation Capability: The Role of Transformational Leadership and Organizational Learning. International Journal of Business Administration, 9(5), 1-10.

Wang, S., \& Noe, R. A. (2010). Knowledge sharing: A review and directions for future research. Human Resource Management Review, 20(2), 115-131. https://doi.org/10.1016/j.hrmr.2009.10.001

Wang, Z., \& Wang, N. (2012). Knowledge sharing, innovation and firm performance. Expert Systems With Applications, 39(10), 8899-8908. https://doi.org/10.1016/j.eswa.2012.02.017

Wang, Z., Sharma, P. N., \& Cao, J. (2016). From knowledge sharing to firm performance: A predictive model comparison. Journal of Business Research, 69(10), 4650-4658. https://doi.org/10.1016/j.jbusres.2016.03.055

Weerawardena, J., \& Mavondo, F. T. (2011). Capabilities, innovation and competitive advantage. Industrial Marketing Management, 40(8), 1220-1223. https://doi.org/10.1016/j.indmarman.2011.10.012

Yang, Z., Nguyen, V. T., \& Le, P. B. (2018). Knowledge sharing serves as a mediator between collaborative culture and innovation capability: an empirical research. Journal of Business \& Industrial Marketing, 33(7), 958-969.

Zollo, M., \& Winter, S. G. (2002). Deliberate learning and the evolution of dynamic capabilities. Organization Science, 13(3), 339-351. https://doi.org/10.1287/orsc.13.3.339.2780 